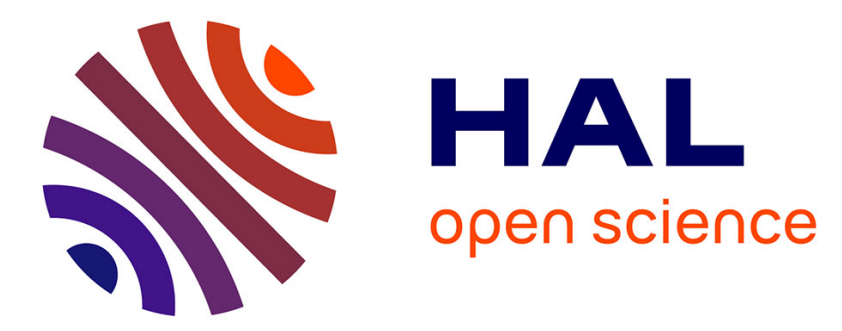

\title{
Direct coating of carbon-supported catalysts on monoliths and foams - Singular behaviour of Pd/MWCNT
}

Florica Simescu-Lazar, Tesnim Chaieb, Stéphanie Pallier, Laurent Veyre, Régis Philippe, Valérie Meille

\section{To cite this version:}

Florica Simescu-Lazar, Tesnim Chaieb, Stéphanie Pallier, Laurent Veyre, Régis Philippe, et al.. Direct coating of carbon-supported catalysts on monoliths and foams - Singular behaviour of Pd/MWCNT. Applied Catalysis A : General, 2015, 508, pp.45 - 51. 10.1016/j.apcata.2015.09.042 . hal-01925616

\section{HAL Id: hal-01925616 https://univ-lyon1.hal.science/hal-01925616}

Submitted on 9 Apr 2019

HAL is a multi-disciplinary open access archive for the deposit and dissemination of scientific research documents, whether they are published or not. The documents may come from teaching and research institutions in France or abroad, or from public or private research centers.
L'archive ouverte pluridisciplinaire $\mathbf{H A L}$, est destinée au dépôt et à la diffusion de documents scientifiques de niveau recherche, publiés ou non, émanant des établissements d'enseignement et de recherche français ou étrangers, des laboratoires publics ou privés. 


\title{
Direct coating of carbon-supported catalysts on monoliths and foams - singular behaviour of $\mathrm{Pd} / \mathrm{MWCNT}$
}

\author{
Florica Simescu-Lazar ${ }^{\mathrm{a}}$, Tesnim Chaieb ${ }^{\mathrm{a}}$, Stéphanie Pallier ${ }^{\mathrm{a}}$, Laurent \\ Veyre $^{\mathrm{b}}$, Régis Philippe ${ }^{\mathrm{a}}$, Valérie Meille ${ }^{\mathrm{a}, *}$ \\ Université de Lyon, Institut de Chimie de Lyon \\ ${ }^{a}$ Laboratoire de Génie des Procédés Catalytiques, CNRS, CPE Lyon, 43 bd du 11 \\ novembre 1918, 69616 Villeurbanne cedex, France \\ ${ }^{b}$ Laboratoire de Chimie, Catalyse et Procédés de polymérisation, CNRS, CPE Lyon, \\ UCBL, 43 bd du 11 novembre 1918, 69616 Villeurbanne cedex, France
}

\begin{abstract}
Monolith or foam substrates were coated with various $\mathrm{Pd} / \mathrm{C}$ suspensions by the washcoating method. The resulting structured catalysts were characterised by thermal analysis (TGA), physisorption of nitrogen (BET method) and electron microscopies (SEM and TEM). Their catalytic activity was evaluated in the model reaction of nitrobenzene hydrogenation. It was found that depending on the carbon source (carbon black, activated carbon or carbon nanotubes), the $\mathrm{Pd} / \mathrm{C}$ deposits were more or less resistant to the coating procedure. All the samples were adherent to the substrates, but only $\mathrm{Pd} / \mathrm{MWCNT}$ was still highly active after coating. The one-step deposition of nanotubes-based catalysts does not alter significantly the catalytic properties of the catalyst and is a promising alternative to nanotube layers grown in situ.
\end{abstract}

Keywords: Carbon coating, Carbon nanotubes, Pd/C, Structured catalytic reactors, Nitrobenzene hydrogenation, Activated carbon

\footnotetext{
*Corresponding author

Email address: vme@lgpc.cpe.fr, tel: +33 (0)4 72431755 - Fax: +33 (0) 472431673 (Valérie Meille)
} 


\section{Introduction}

The direct coating of a carbon-supported catalyst on a structure is an important topic linked to the growing use of structured catalytic reactors, which necessitates adherent and uniform catalytic layers of a few micrometer thickness. In a previous paper, we compared the synthesis of a carbon layer to the use of a suspension made of carbon black [1]. The suspension method was found to produce adherent carbon layers with appropriate textural properties to support a metal catalyst. The use of other sources of carbon such as activated carbon or carbon nanotubes is nevertheless worth of investigations because of better textural properties leading often to better selectivities and activities [2]. In the literature, getting carbon nanofibers/nanotubes (CNF/CNT) on structured substrates (e.g. stainless steel foams) was mainly obtained by direct growing of CNT [3] or CNF [4-7] on the substrates. Another method, based on the use of an aqueous suspension of CNT implies electrophoresis [8]. The use of a direct coating by immersion in a CNT suspension was almost ignored, except in the work of Lu et al. [9], which consisted in repeating the successive immersion of a polyurethane foam (or of a ceramic monolith) in a CNT suspension and in a polymer solution. The final coating formed by 6 bilayers was dried and used to immobilize some enzymes. Concerning activated carbon, and even more commercial metal/C catalysts, no example of coating through the use of a suspension was reported to the best of our knowledge.

The carbon draws attention in heterogeneous catalysis due to its advantageous properties such as chemical inertness and high specific surface area. Moreover, it is the most widely present catalyst support in the pharmaceutical industry [10]. In this work, three different types of carbon were used to prepare $\mathrm{Pd}$ /carbon catalysts: carbon black (CB), activated carbon (AC) and multi-wall carbon nanotubes (MWCNT). The home-made catalysts, as well as a commercial $\mathrm{Pd} / \mathrm{C}$, were further deposited on foam substrates by the suspension method. The catalysts developed in this work were used in nitrobenzene hydrogenation. The catalytic performances of the prepared catalysts have been compared to that obtained in the same conditions with the commercial one. Reducing the diffusion problems, especially in liquidphase reaction medium $[11,12]$, the carbon nanotubes are expected to be an appropriate support for nitrobenzene hydrogenation. The objective of the work was to check whether a very simple coating method could allow to get structured $\mathrm{Pd} / \mathrm{C}$ catalysts with high activity, and to find the most appropri- 
ate carbon support (among activated carbon, carbon black and multi-wall carbon nanotubes) to achieve this goal.

\section{Experimental}

\subsection{Chemicals}

Multi-wall carbon nanotubes (MWCNT graphistrength), activated carbon (SX Ultra cat), and carbon black (Cabot Vulcan XC72) were used as carbon supports to prepare $\mathrm{Pd} / \mathrm{C}$ catalyst powders, by impregnation of the carbon with palladium chloride (Sigma-Aldrich). The data supplied by the providers are given in Table 1 . A Johnson Matthey $4.9 \% \mathrm{Pd} / \mathrm{C}$ powder catalyst (containing 59.8 wt- $\%$ water) was also used. $\mathrm{H}_{2} \mathrm{SO}_{4}(98 \%), \mathrm{HNO}_{3}(65 \%$ ), $\mathrm{HCl}(36.5 \%)$ and $\mathrm{NaOH}(99 \%)$ were purchased from Sigma-Aldrich. 
Table 1: Characteristics of the different carbon materials, provided by the suppliers

\begin{tabular}{|c|c|c|c|c|}
\hline Name & Reference & Type of carbon & Provider & Characteristics \\
\hline MWCNT & $\begin{array}{l}\text { MWCNT } \\
\text { graphistrength } \mathrm{C} 100\end{array}$ & Carbon nanotubes & Arkema & $\begin{array}{l}\text { NT diameter } 10-15 \mathrm{~nm} \text {, length } \\
0.1-10 \mu \mathrm{m} \text {; aggregates } 50-150 \mu \mathrm{m}\end{array}$ \\
\hline $\mathrm{AC}$ & SX Ultra cat & Activated carbon & Norit & \\
\hline $\mathrm{CB}$ & Vulcan XC72 & Carbon black & Cabot & $264 \mathrm{~kg} / \mathrm{m}^{3}$ \\
\hline JM & $\mathrm{Pd} / \mathrm{C}$ & $\mathrm{Pd}$ on activated carbon & $\begin{array}{l}\text { Corp. } \\
\text { Johnson } \\
\text { Matthey }\end{array}$ & $4.9 \% \mathrm{Pd}$ \\
\hline
\end{tabular}




\subsection{Structures}

Stainless steel foams (40 pores per inch, from Porvair Advanced Materials) and cordierite monoliths (64 cpsi, Corning) were used as structures to host the carbonaceous coatings. The foams were cut into hollow cylindrical pieces of $46 \mathrm{~mm}$ external diameter, $30 \mathrm{~mm}$ internal diameter and $11 \mathrm{~mm}$ thickness by electric discharge method (EDM). The monolith pieces were ca. $2 \mathrm{~cm} \mathrm{x}$ $2 \mathrm{~cm} \mathrm{x} 1 \mathrm{~cm}$. Plates of AISI 316L stainless steel (ThyssenKrupp), $80 \mathrm{~mm}$ long, $30 \mathrm{~mm}$ wide and $2 \mathrm{~mm}$ thick, about $20 \mathrm{~g}$, were used as non structured supports.

\subsection{Pretreatment of the structures}

Cordierite monoliths were simply rinsed in ethanol and dried. Stainless steel foams were pretreated by successive steps (thermal treatment and chemical basic treatment) according to a recent work [13].

\subsection{MWCNT purification and functionalization}

The MWCNT (purity ca. 85 wt- $\%$ ) used for this work were obtained by chemical vapour deposition (CVD) from ethylene on $\mathrm{Fe} / \mathrm{Al}_{2} \mathrm{O}_{3}$ catalyst at $650{ }^{\circ} \mathrm{C}$. For purification purposes (removal of catalyst), $500 \mathrm{~mL}$ of $\mathrm{H}_{2} \mathrm{SO}_{4}$ (95 vol\%) were slowly dropped under constant stirring into a suspension of $20 \mathrm{~g}$ MWCNT in $500 \mathrm{~mL}$ of distilled water. The suspension was refluxed at $140^{\circ} \mathrm{C}$ for $3 \mathrm{~h}$. Then, without cooling, the MWCNT were filtered on a fritted glass funnel. Then, they were washed with hot distilled water until a stable $\mathrm{pH}$ (6) and dried at $120^{\circ} \mathrm{C}$ for 2 days. Two pictures of MWCNT before (a) and after (b) purification step are given in Figure 1, showing no particular modification of the nanotube texture. The important decrease of brightness is due to the removal of iron species.

In order to further functionalize the surface of carbon nanotubes with acidic functions that may enhance both the adherence of the coating on the substrate and the dispersion of metallic active sites on the carbonaceous support, $1 \mathrm{~g}$ of purified nanotubes were mixed with $50 \mathrm{~mL}$ of nitric acid (65 $\%$ ) at $120^{\circ} \mathrm{C}$ for $8 \mathrm{~h}$ under stirring. Then, the MWCNT were filtered on a hot fritted glass funnel and washed with hot distilled water until a stable $\mathrm{pH}$ value (ca. 6). The nanotubes were then dried at $120^{\circ} \mathrm{C}$ for 2 days [14].

\subsection{Catalyst preparation}

$\mathrm{Pd} / \mathrm{C}$ catalysts were prepared by impregnating the carbonaceaous supports (AC, $\mathrm{CB}$ and MWCNT) with an acidic aqueous solution of palladium 

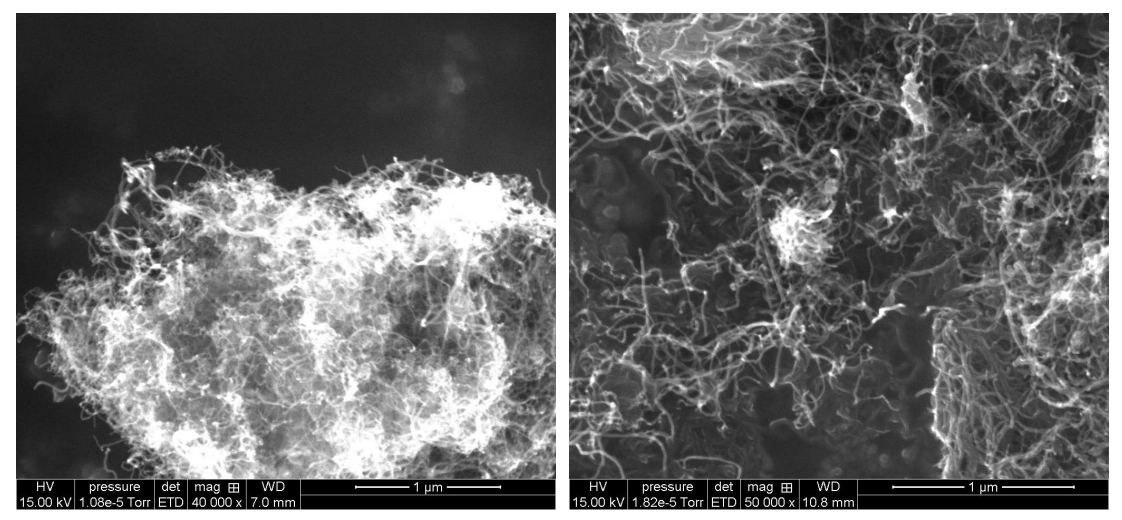

Figure 1: SEM images of MWCNT : (a) before and (b) after purification. The scale is 1 $\mu \mathrm{m}$.

chloride. $4 \mathrm{~g}$ of carbon were contacted with $0.2 \mathrm{~g}$ of $\mathrm{PdCl}_{2}$ in $50 \mathrm{~mL}$ hydrochloric acid solution $(\mathrm{pH}=3)$. After 4 hours stirring, the solvent was evaporated at $60{ }^{\circ} \mathrm{C}$ under reduced pressure using a rotary evaporator and the powder was dried in the oven at $110^{\circ} \mathrm{C}$ during one night.

\subsection{Coating method}

The standard suspension was prepared as follows: $5.4 \mathrm{~g}$ of carbon supported catalyst, $36 \mathrm{~mL}$ of water and $1 \mathrm{~mL}$ of Triton X-100 were stirred together and the suspension was kept in an ultrasound apparatus during 50 min at room temperature. $0.8 \mathrm{~g}$ dextrine was added as a binder. In the case of $\mathrm{Pd} / \mathrm{MWCNT}$, as it is highly porous, only $2.7 \mathrm{~g}$ were used instead of $5.4 \mathrm{~g}$. Pd/AC and Pd/MWCNT based suspensions were ball-milled for $1 \mathrm{~h}$ to avoid the aggregation of the carbon particles. The substrates to coat were immersed in the $\mathrm{Pd} / \mathrm{C}$ suspension and the excess liquid was blown with compressed air. The organic additives were decomposed during the thermal treatment at 450 or $550{ }^{\circ} \mathrm{C}$ under nitrogen flow $(0.5 \mathrm{~L} / \mathrm{min})$ during $5 \mathrm{~h}$. In the case of stainless steel plates, the catalytic layer was scrapped after the thermal treatment. In the case of monoliths, the coating thickness was about $10 \mu \mathrm{m}$ [1]; the samples were not used as entire objects but were crushed after the thermal treatment and used as a powder in the catalytic tests. Note that all the catalysts and coatings have been reproduced at least twice. 


\subsection{Characterization methods}

\subsubsection{Carbon}

Nitrogen physisorption measurements were performed with a Micromeritics ASAP 2020 at $-196^{\circ} \mathrm{C}$ using the BET method. Before analysis, the samples were outgased at $300^{\circ} \mathrm{C}$ during $4 \mathrm{~h}$. The pore diameter is an average pore diameter calculated from $4 \mathrm{~V}_{P} / \mathrm{S}_{B E T}$ (cylindric pores). The micropore volume is calculated from t-plot curve. The SEM micrographs of the MWCNT were obtained using a FEI Quanta 250 FEG microscope at the Centre Technologique des Microstructures (CT $\mu$ ) at University of Lyon. Thermogravimetric analysis (TGA) of the carbonaceous materials were performed to check their quality and their resistance to pyrolysis. TGA experiments were performed in a Mettler Toledo TGA/DSC1 thermobalance [15]. About $10 \mathrm{mg}$ of carbon were placed in platinum crucible and heated under air flow $\left(30 \mathrm{~mL} \cdot \mathrm{min}^{-1}\right)$. The samples were heated from $20^{\circ} \mathrm{C}$ to $1000^{\circ} \mathrm{C}$ at $10^{\circ} \mathrm{C} / \mathrm{min}$.

\subsubsection{Palladium}

The Pd loading of the catalysts was checked by ICP-AES. Electron Microscopy was performed at the Centre Technologique des Microstructures $(\mathrm{CT} \mu)$ at University of Lyon. Transmission electron microscopy (TEM) and High angle annular dark field-scanning transmission electron microscopy (HAADF-STEM) images were obtained using a JEOL 2100F FEG-200kV. The samples for TEM analysis were prepared onto ultrathin $\mathrm{C}$ film on holey carbon support film.

\subsection{Catalytic tests}

The catalyst activity of coated and non-coated $\mathrm{Pd} / \mathrm{C}$ was evaluated using the model reaction of nitrobenzene hydrogenation. This reaction is known to be selective towards aniline when a $\mathrm{Pd} / \mathrm{C}$ catalyst is used $[13,16,17]$. In this study, the catalyst was either a $\mathrm{Pd} / \mathrm{C}$ powder (suffix $-\mathrm{P}$ for the non-coated powder or P-p for the powder scrapped from a coated plate), or a crushed $\mathrm{Pd} / \mathrm{C} /$ monolith powder (suffix $-\mathrm{M}$ ), or a $\mathrm{Pd} / \mathrm{C} /$ foam cylinder (suffix $-\mathrm{F}$ ). It was introduced with $170 \mathrm{~mL}$ of ethanol/water (9:1 volume) in a stainless steel (AISI316) batch reactor of $300 \mathrm{~mL}$. A gas-inducing turbine (TOP industrie) at a stirring rate of $1800 \mathrm{rpm}$ was used for all the experiments. In the case of $\mathrm{Pd} / \mathrm{C} /$ foam, the catalytic cylinder was maintained at half-height of the liquid volume and used instead of a Mahoney-Robinson basket (for further details, see [13]). In the case of the catalytic powders, baffles were introduced 
in the reactor to improve the stirring. The catalyst was pre-activated under pure hydrogen during 1 hour at the same temperature $\left(40^{\circ} \mathrm{C}\right)$ and pressure (3 bars) than the catalytic test. Nitrobenzene $(3 \mathrm{~mL})$ was then added to the mixture through a pressurised addition funnel. Hydrogen was supplied from an upstream-calibrated reservoir and was fed to the reactor at constant pressure via a pressure regulator. The pressure decrease in this reservoir provided the hydrogen consumption rate and thus the reaction rate. The selectivity to aniline was checked by GC. No other species than nitrobenzene and aniline was detected and the mass balance was respected.

To compare the activities of different catalysts, it is usual to express reaction rates in $\mathrm{mol} / \mathrm{s} / \mathrm{surface}$ atoms. In the present study, the objective is not to focus on the intrinsic activity of one catalyst and its possible link with the metal-support interactions. It is not expected that the different $\mathrm{Pd} / \mathrm{C}$ catalysts present different activities per surface atoms of Pd. The goal is to determine how different catalysts are resistant to the developed coating procedure. The reaction rates are thus expressed in mol/s/g(Pd), which provides a first idea on how the catalyst has been modified during coating. Indeed, a decrease in the reaction rate (per gram of $\mathrm{Pd}$ ) indicates that either the catalyst has evolved (sintering, metal leaching ...) or that a non negligible amount of pores have been blocked and some metal particles become no longer accessible.

\section{Results and discussion}

The kinetics of the carbon thermal decomposition, under oxidative condition, was studied by TGA under air flow to quantify the purity and the stability of the carbons at high temperatures. The different weight-loss steps correspond to different inflection points in the thermogravimetric curves. Figure 2 shows that only one weight loss is observed for all the carbons, except AC. It has been noted that the samples start to decompose at $450-500^{\circ} \mathrm{C}$, even without Pd catalyst. This justifies that all the thermal treatments of the carbon layers (and even more the $\mathrm{Pd} / \mathrm{C}$ layers) should be performed under nitrogen atmosphere. For AC, a first weight loss is observed at ca. $110^{\circ} \mathrm{C}$. This is due to the presence of water. A high level of impurities is present for activated carbon (10\%) and carbon black (6\%), but lower than that of MWCNT before purification step (14\%). After purification of MWCNT, $6 \%$ of impurities remained. This result was explained by the presence of some 
impurities not accessible during purification, such as encapsulated iron, iron carbide or other metallic species used in the MWCNT growth [18].

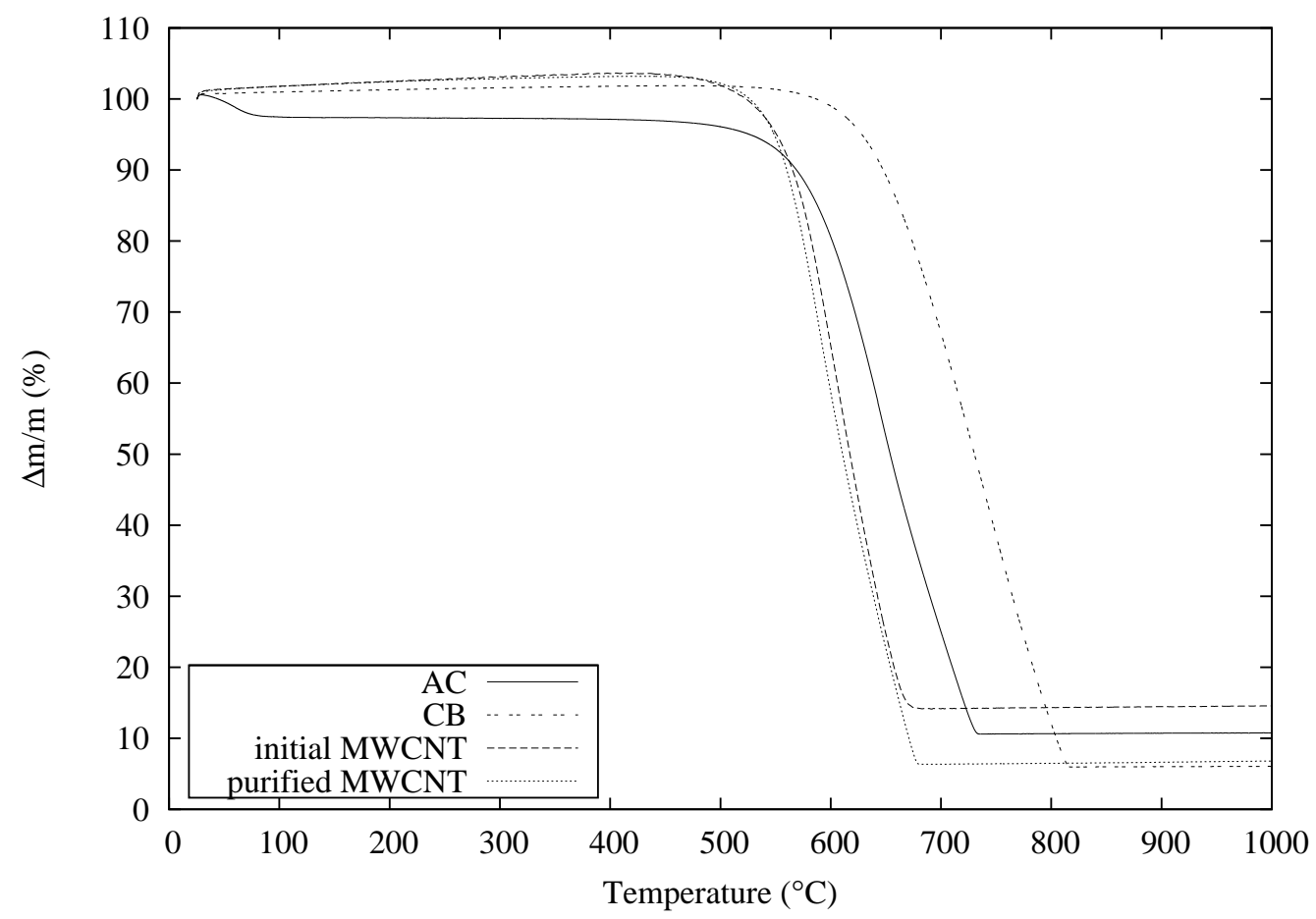

Figure 2: Thermo-gravimetric analysis, under air flow, of the different carbon supports

Different samples of $\mathrm{Pd} / \mathrm{C}$ immobilized on plates, monoliths and foams have been prepared. A high adherence of the layer on the substrate was obtained in all the cases. The catalyst loading on the metallic foam was about 2 wt-\%. An example of coated foams is presented in Figure 3.

The different catalysts have been evaluated in the hydrogenation of nitrobenzene. Before presenting the catalytic activity, it is important to mention that all the coated foams that have been used as entire objects did not lose any traces of catalyst during the catalytic test. The weigh of the coated foams was the same before and after the test. External mass transfer limitations were studied by varying catalyst content and stirring speed and were clearly excluded. On the contrary, internal mass transfers are likely and in the following, apparent initial reaction rates including this possible resistance are discussed. The comparison reflects both the impact of the coating process 


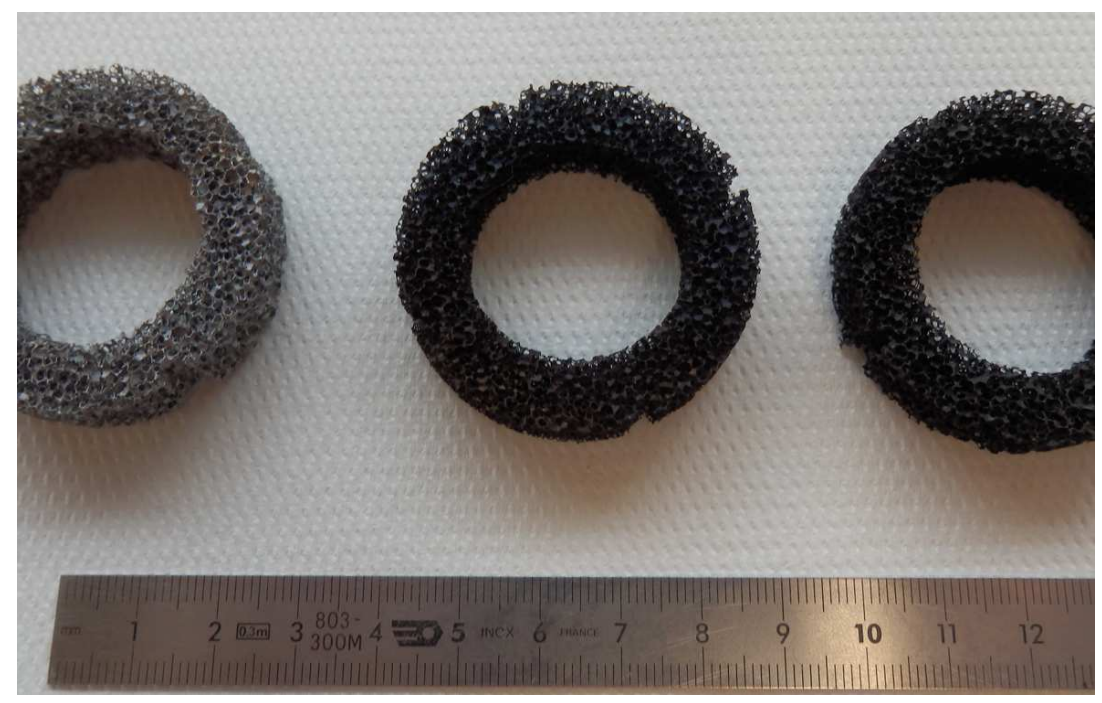

Figure 3: From left to right: virgin foam, JM and Pd/MWCNT coated on foam cylinders

on intrinsic activity and the possible variations in internal mass transfer efficiency due to the catalyst structure (porous volume, tortuosity, pore sizes). The results are presented in Table 2 . The initial hydrogen consumption rates per gram of palladium have also been plotted as histograms for the different catalysts (Figure 4). Note that the aniline production is about 3 times lower than the hydrogen consumption, due to the reaction stoichiometry. The activity of the commercial catalyst is the highest, but this catalyst does not survive to coating: the activity of the coated substrates, even the scrapped coated-plate, is one order of magnitude lower than the non-transformed powder.

Unfortunately, the initial activity of the powders scrapped from coated plates (P-p) is, for all catalysts, lower than the non-transformed powder catalysts $(\mathrm{P})$, even if the effect is worse for activated carbons ( $\mathrm{JM}$ and $\mathrm{Pd} / \mathrm{AC}$ ). Please note that the higher activity measured for JM-M than JM-P-p is not considered as relevant and may be due to a temperature gradient in the oven used for the calcination step. One result is nevertheless very promising. $\mathrm{Pd} / \mathrm{MWCNT}$, in all shapes, shows a high activity. The higher activity of the powder $\mathrm{Pd} / \mathrm{MWCNT}$ than $\mathrm{Pd} / \mathrm{AC}$ has already been reported [19, 20], but the fact that the $\mathrm{Pd} / \mathrm{MWCNT}$ can be coated and that its activity remains very high is a new result opening the way for hierarchical catalytic objects. Indeed for the first time we show a robust combination of structured cata- 
lysts and structured reactors at a larger scale than those obtained by direct CVD growth [21, 22].

Moreover, in the case of the coated foams, used as entire objects, it was possible to check that the catalyst was not leached from the substrate. The adhesion on stainless steel foams was confirmed by weight measurement of the catalytic foam after the catalytic test. All the samples calcinated at $550^{\circ} \mathrm{C}$ never showed more than $2 \mathrm{wt}-\%$ catalyst loss. On the contrary, a calcination at $450^{\circ} \mathrm{C}$ was not sufficient and some $\mathrm{Pd} / \mathrm{C}$ was detected in the nitrobenzene solution. Concerning the metal leaching, a previous study about $\mathrm{Pd} / \mathrm{CB}$ on foams has shown that there was no metal leaching. The reuse of the catalyst for several cycles revealed some catalyst deactivation, but an electrochemical regeneration, using cyclic voltamperometry in acidic medium (see [13]), allowed to regain the initial productivity of the catalyst. 


\begin{tabular}{|c|c|c|c|c|c|}
\hline Catalyst & Support/substrate & $\begin{array}{c}\mathrm{wt} \% \mathrm{C} \\
\mathrm{g}_{C} / 100 \mathrm{~g}_{\text {substrate }}\end{array}$ & $\begin{array}{l}\mathrm{wt} \% \mathrm{Pd} \text { on } \mathrm{C} \\
\mathrm{g}_{P d} / 100 \mathrm{~g}_{C}\end{array}$ & $\begin{array}{c}\text { Initial } \mathrm{H}_{2} \text { consumption }{ }^{1} \\
\text { mols }^{-1} \mathrm{~g}_{C}^{-1}\end{array}$ & $\begin{array}{c}\text { Initial } \mathrm{H}_{2} \text { consumption } \\
\mathrm{mmols}^{-1} \mathrm{~g}_{P d}^{-1}\end{array}$ \\
\hline JM-P & Commercial catalyst & - & 4.9 & 2800 & 54.5 \\
\hline JM-P-p & JM scrapped from steel plate (p) & - & 4.9 & 189 & 3.7 \\
\hline JM-F & $\mathrm{JM} /$ foam & 1.4 & 4.9 & 103 & 2.0 \\
\hline JM-M & $\mathrm{JM} /$ monolith & 7.6 & 4.9 & 347 & 7.1 \\
\hline $\mathrm{Pd} / \mathrm{AC}-\mathrm{P}$ & Home made catalyst on activated carbon & - & 2.7 & 526 & 19.0 \\
\hline $\mathrm{Pd} / \mathrm{AC}-\mathrm{P}-\mathrm{p}$ & Pd/AC scrapped from steel plate & - & 2.7 & 171 & 6.2 \\
\hline $\mathrm{Pd} / \mathrm{AC}-\mathrm{F}$ & $\mathrm{Pd} / \mathrm{AC} /$ foam & 1.5 & 2.7 & 83.6 & 3.0 \\
\hline $\mathrm{Pd} / \mathrm{AC}-\mathrm{M}$ & $\mathrm{Pd} / \mathrm{AC} /$ monolith & 5.5 & 2.7 & 78.7 & 2.9 \\
\hline $\mathrm{Pd} / \mathrm{CB}-\mathrm{P}$ & Home made on carbon black & - & 2.7 & 430 & 15.6 \\
\hline Pd/CB-P-p & $\mathrm{Pd} / \mathrm{CB}$ scrapped from steel plate & - & 2.7 & 160 & 5.8 \\
\hline $\mathrm{Pd} / \mathrm{CB}-\mathrm{F}$ & $\mathrm{Pd} / \mathrm{CB} /$ foam & 2.8 & 2.7 & 104 & 3.8 \\
\hline $\mathrm{Pd} / \mathrm{CB}-\mathrm{M}$ & $\mathrm{Pd} / \mathrm{CB} /$ monolith & 1.5 & 1.7 & 13.9 & 1.0 \\
\hline Pd/MWCNT-P & Pd/MWCNT on carbon nanotubes & - & 2.7 & 702 & 25.0 \\
\hline $\mathrm{Pd} / \mathrm{MWCNT}-\mathrm{P}-\mathrm{p}$ & Pd/MWCNT scrapped from steel plate & - & 2.7 & 444 & 14.6 \\
\hline $\mathrm{Pd} / \mathrm{MWCNT}-\mathrm{F}$ & $\mathrm{Pd} / \mathrm{MWCNT} /$ foam & 1.3 & 2.7 & 350 & 13.3 \\
\hline $\mathrm{Pd} / \mathrm{MWCNT}-\mathrm{M}$ & $\mathrm{Pd} / \mathrm{MWCNT} /$ monolith & 1.3 & 2.7 & 320 & 12.0 \\
\hline
\end{tabular}

${ }^{1}$ Nitrobenzene hydrogenation experiments at 3 bars, $40{ }^{\circ} \mathrm{C}$. 


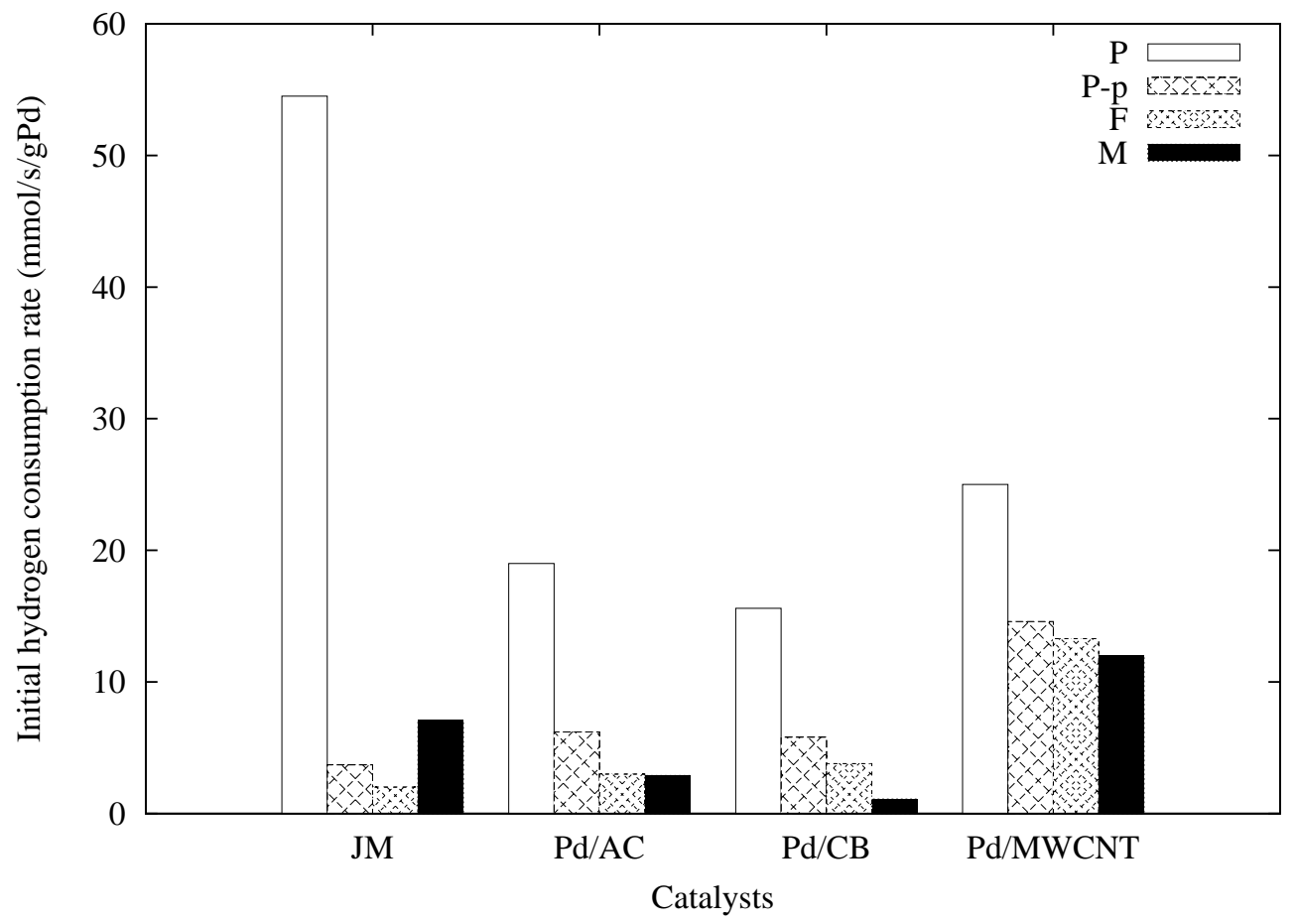

Figure 4: Initial hydrogen consumption rates during nitrobenzene hydrogenation (3 bars, $40{ }^{\circ} \mathrm{C}$ ) for the different catalysts. P refers to the initial powder, P-p to the scrapped powder, $\mathrm{F}$ to the coated foam and $\mathrm{M}$ to the crushed coated monolith 
Table 3: Textural properties of the catalysts

\begin{tabular}{cccccc} 
Reference & $\begin{array}{c}\text { BET surface area } \\
\left(\mathrm{m}^{2} / \mathrm{g}\right)\end{array}$ & $\begin{array}{c}\text { Minimum pore } \\
\text { diameter }(\mathrm{nm})\end{array}$ & $\begin{array}{c}\text { Porous volume } \\
(\mathrm{mL} / \mathrm{g})\end{array}$ & $\begin{array}{c}\text { Micropore } \\
\mathrm{area}^{2}\left(\mathrm{~m}^{2} / \mathrm{g}\right)\end{array}$ & $\begin{array}{c}\text { Microporous } \\
\text { volume }(\mathrm{mL} / \mathrm{g})\end{array}$ \\
\hline JM-P & 845 & 3 & 0.6 & 456 & 0.21 \\
JM-P-p & 704 & 3 & 0.5 & 372 & 0.17 \\
JM-M & 485 & 3 & 0.4 & 261 & 0.12 \\
Pd/AC-P & 944 & 3 & 0.7 & 514 & 0.23 \\
Pd/AC-P-p & 1007 & 3 & 0.8 & 543 & 0.20 \\
Pd/AC-M & 902 & 3 & 0.7 & 437 & 0.20 \\
Pd/CB-P & 224 & 7 & 0.4 & 105 & 0.05 \\
Pd/CB-M & 212 & 8 & 0.4 & 67 & 0.03 \\
Pd/MWCNT-P & 249 & 14 & 0.8 & 21 & 0.01 \\
Pd/MWCNT-M & 296 & 16 & 1.2 & 58 & 0.02
\end{tabular}

${ }^{2}$ The micropore area is calculated by the difference between the BET surface area and the external t-plot area 
To explain the activity change after coating, the textural properties of the catalysts were compared before and after coating. They are reported in Table 3. The textural properties of the home made catalysts $(\mathrm{Pd} / \mathrm{AC}, \mathrm{Pd} / \mathrm{CB}$ and $\mathrm{Pd} / \mathrm{MWCNT}$ ) appear to be weakly affected by the coating procedure. For the commercial catalyst, a strong effect of coating on the micropore volume (and thus on the micropore area) is noticed. Some micropores seem to be plugged after the coating procedure. Part of the activity decrease may thus be due to an impossible access to $\mathrm{Pd}$ in plugged micropores. Moreover, the presence of micropores may limit the mass transfer through the coating, since the characteristic size of the catalyst is higher for the washcoat (thickness around $10 \mu \mathrm{m})$ than for the powder $\left(\mathrm{d}_{p} / 6=5 \mu \mathrm{m}\right)$. Nevertheless, the activity decrease of all the catalysts after coating can not result solely from textural properties. Palladium sintering during the coating process was then suspected to be the main explanation of this activity loss.

A direct visualisation of the size of the palladium particles on the different carbon surfaces was performed by TEM and HAADF-STEM. The TEM images of the commercial catalyst reveal a very heterogeneous surface (Figure 5), with a first indication of a particle growing after coating. From the HAADF-STEM images of the same catalyst, the z-contrast clearly reveals the $\mathrm{Pd}$ particles as bright spots on the images. An increase of the particle size due to the coating process is clearly evidenced by comparing left and right pictures of Figure 6. Important sintering is suspected to occur during the calcination step. This sintering may be partly due to the high metal loading of the catalyst. Note that the important heterogeneity of the Pd particle size (from a few nanometers to several hundreds of nanometers) and the variable and low contrast between carbon of various thicknesses and Pd particles do not allow to provide relevant average particle sizes and quantitative particle size distributions.

In the case of the nanotube-supported catalysts, TEM pictures, presented in Figure 7, show smaller and more uniform particles than the commercial one. Most of the palladium particles seem to be inside the nanotubes of the non-coated catalyst powder (left picture). After coating, the palladium particle size has surely increased (right picture) but to a less extent than in the case of the commercial JM catalyst. It seems like the palladium sintering is prevented when supported on carbon nanotubes. This is in accordance with other reported results $[2,12,23,24]$ and is correlated to the strong metalsupport affinity developed between MWCNT surface and metallic nanoparticles. Indeed, $\pi$-d electronic interactions and peculiar charge transfers ensure 

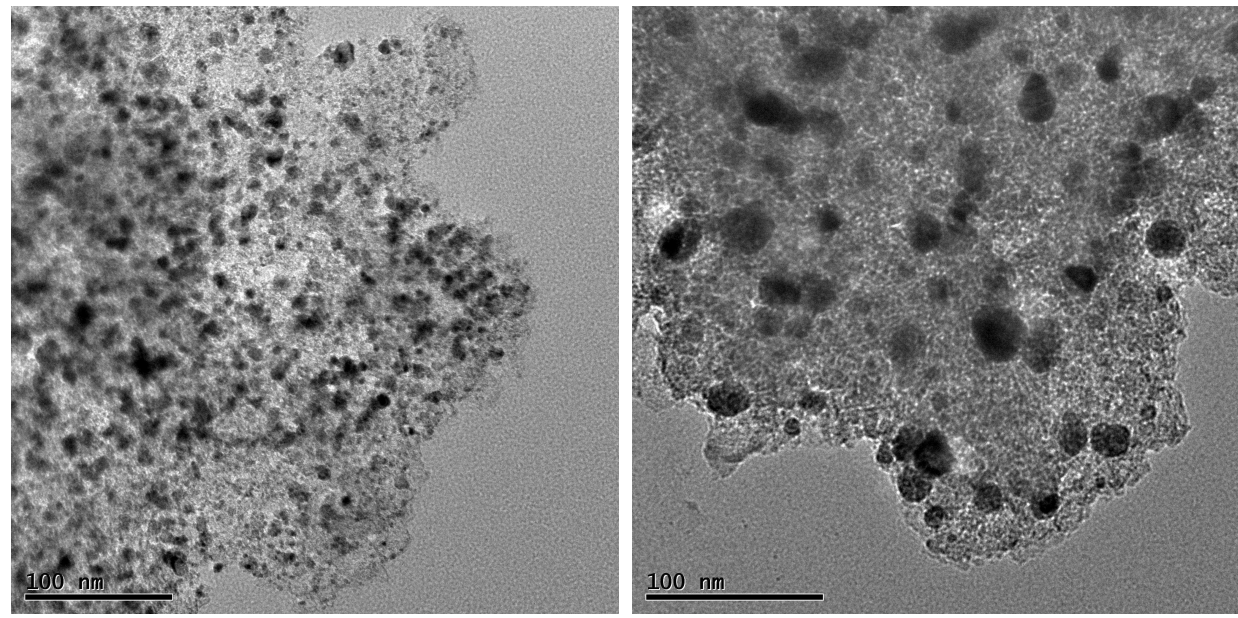

Figure 5: TEM images of the initial JM powder (JM-P, left) and the scrapped one (JM$\mathrm{P}-\mathrm{p}$, right). The scale is $100 \mathrm{~nm}$.
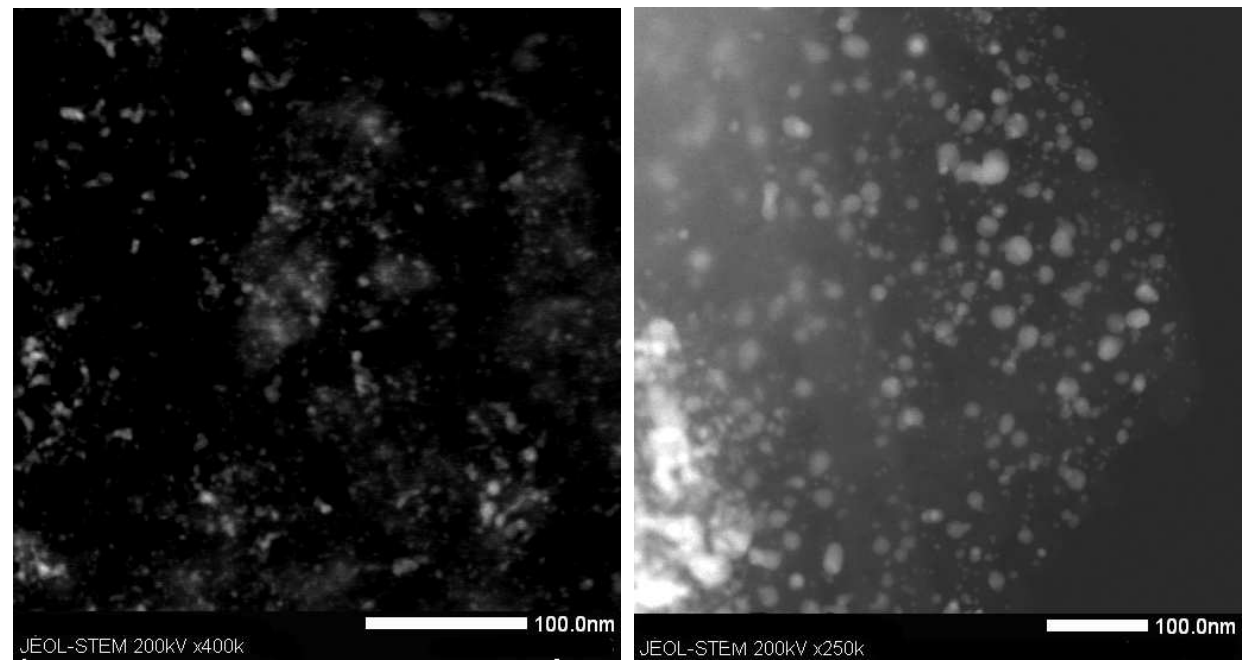

Figure 6: HAADF-STEM images of the initial JM powder (JM-P, left) and the scrapped one (JM-P-p, right). The scale is $100 \mathrm{~nm}$.

a very good electronic affinity between the metallic clusters and the curved nanotube surface, resulting in a strong and stable anchoring preventing and limiting migration of nanoparticles. This can explain why the activity of this catalyst is weakly affected by the coating process.

To go further with the deactivation of the commercial catalyst, one other 

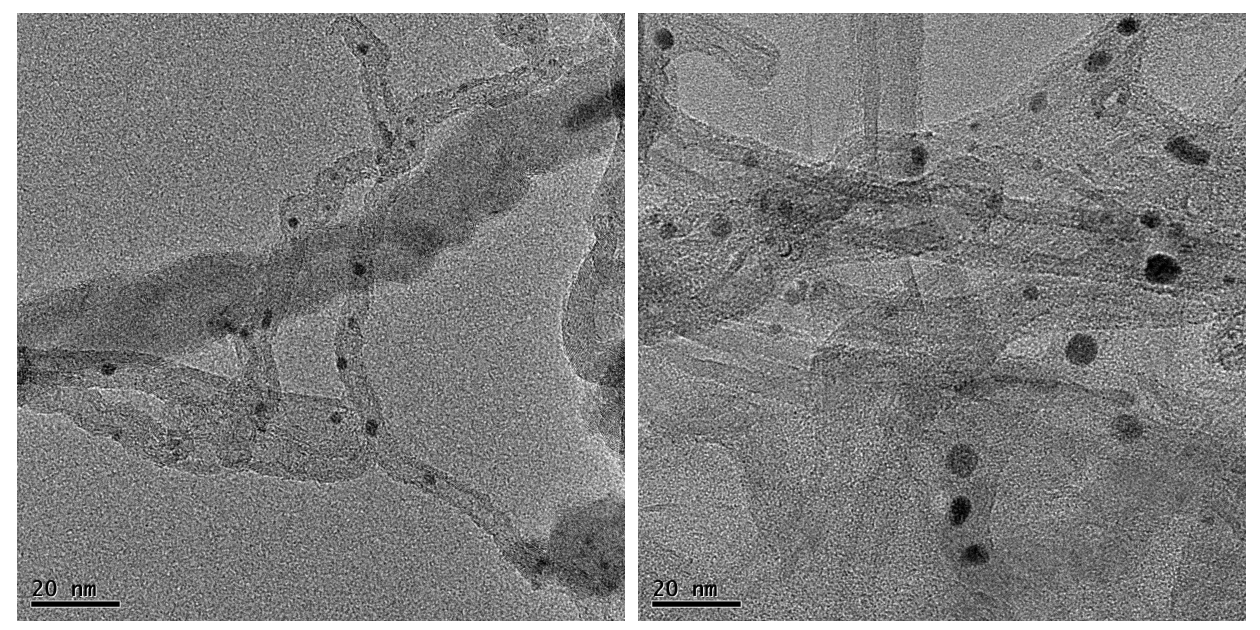

Figure 7: TEM images of the initial Pd/MWCNT powder (Pd/MWCNT-P, left) and scrapped one (Pd/MWCNT-P-p, right). The scale is $20 \mathrm{~nm}$.

factor could also be invoked. Tengco et al. [25] have indeed recently proved that a carbon layer can be formed around the palladium particles when a non-oxidative heat treatment is applied to the catalyst. Our coated catalysts, treated at $550^{\circ} \mathrm{C}$ under nitrogen flow and directly reduced under the reaction conditions were considered to potentially suffer from this problem. A careful observation of palladium particles of the JM-P-p powder by TEM can reveal some carbon-decorated $\mathrm{Pd}$ particles on the edge of the carbon surface (Figure 8). An oxidative treatment was attempted to try to selectively remove this potentially more reactive carbon layer. After 1 hour at $290^{\circ} \mathrm{C}$, the oxidized JM-P-p powder was twice more active than the non-oxidized one. This factor was not considered significant enough to confirm the role of the carbon decoration on the activity decrease and the TEM observation didn't show noticeable differences. Nevertheless, this point should be taken into account in the further studies, to try to avoid the carbon decoration. One solution could be to use another palladium precursor, chloride percursors being suspected to catalyze this carbon decoration [25]. Another option is to study and optimize the removal of this layer.

\section{Conclusions}

Three types of carbons (carbon black, activated carbon and carbon nanotubes) have been used as supports to prepare $\mathrm{Pd} / \mathrm{C} /$ substrate catalysts that 


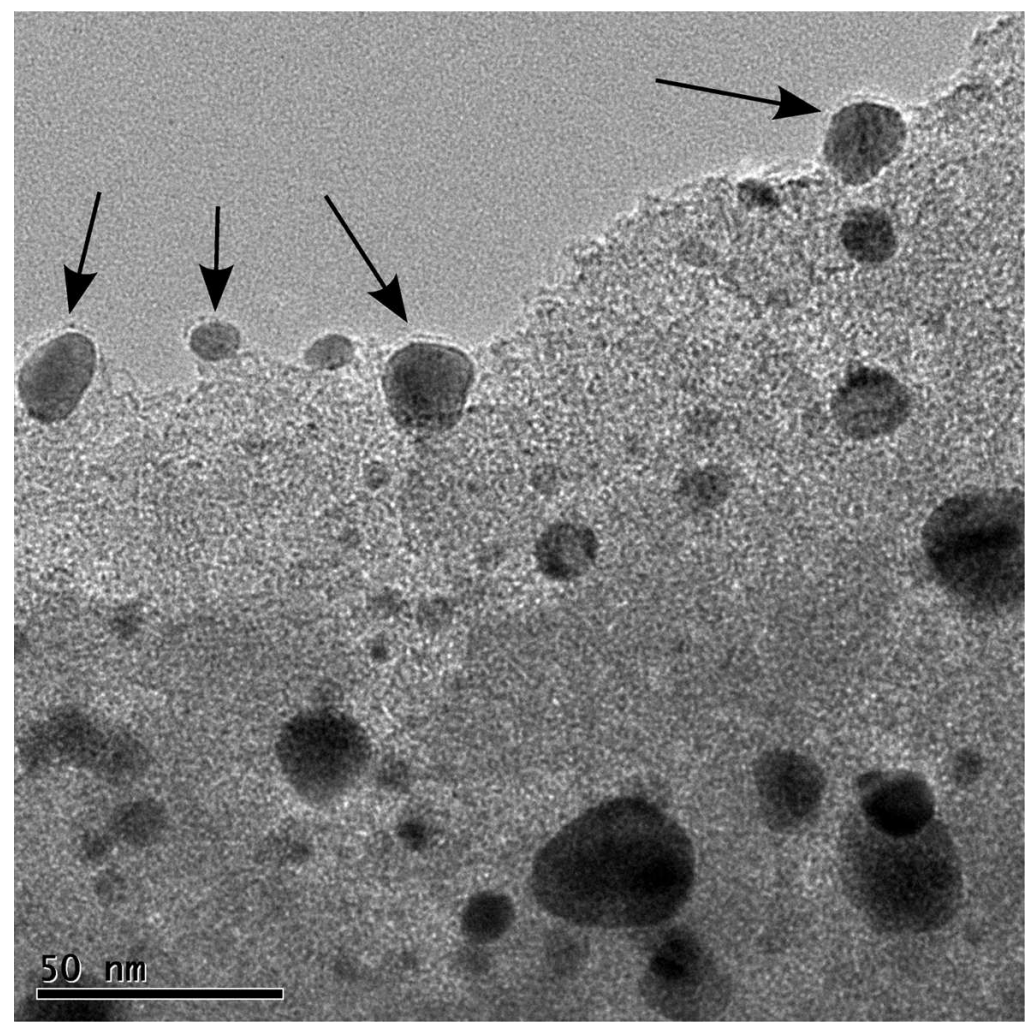

Figure 8: TEM images of the scrapped JM catalyst (JM-P-p). The scale is $50 \mathrm{~nm}$. The arrows indicate possible carbon decoration on Pd particles

were tested for nitrobenzene hydrogenation. The coating method was based on the preparation of an aqueous suspension of the powder catalysts and the deposition on ceramic monoliths and stainless steel foams. Thanks to the grinding of the suspension, and to the appropriate pretreatment of the substrates, the catalyst layers were very adherent to the substrates. Unfortunately, the catalytic activity was reduced during the coating process, due to important sintering of palladium, and especially in the case of high surface area carbons. For that familly of catalysts, carbon alone should be coated first, followed by a palladium impregnation of the coated substrate. In the case of $\mathrm{Pd} / \mathrm{MWCNT}$, the sintering was limited and the catalytic activity after coating was still very high. This result offers a very simple method to get active catalysts in structured reactors. 


\section{Acknowledgements}

This study was performed with the financial support from EU Polycat program (No. CO-IP 246095-2). The authors gratefully acknowledge O. Boyron for ATG analysis and ARKEMA for providing a sample of graphistrength MWCNT.

[1] P. Rodriguez, F. Simescu-Lazar, V. Meille, T. Bah, S. Pallier, I. Fournel, Appl. Catal. A 427-428 (2012) 66-72.

[2] H. Vu, F. Gonçalves, R. Philippe, E. Lamouroux, M. Corrias, Y. Kihn, D. Plee, P. Kalck, P. Serp, J. Catal. 240 (2006) 18-22.

[3] D. R. Minett, J. P. O’Byrne, M. D. Jones, V. P. Ting, T. J. Mays, D. Mattia, Carbon 51 (2013) 327-334.

[4] S. de Loos, J. van der Schaaf, M. de Croon, T. Nijhuis, J. Schouten, Chem. Eng. J. 167 (2011) 671-680.

[5] L. Martínez-Latorre, S. Armenise, E. Garcia-Bordejé, Carbon 48 (2010) $2047-2056$.

[6] D. Thakur, R. Tiggelaar, J. Gardeniers, L. Lefferts, K. Seshan, Chem. Eng. J. 227 (2013) 128-136.

[7] J. Restivo, J. J. M. Órfão, M. F. R. Pereira, E. Garcia-Bordejé, P. Roche, D. Bourdin, B. Houssais, M. Coste, S. Derrouiche, Chem. Eng. J. 230 (2013) 115-123.

[8] B. J. C. Thomas, A. R. Boccaccini, M. S. P. Shaffer, J. Am. Ceram. Soc. 88 (2005) 980982.

[9] J. Lu, R. R. Weerasiri, I. Lee, Biotechnol. Lett. 35 (2013) 181-188.

[10] E. Auer, A. Freund, J. Pietsch, T. Tacke, Appl. Catal. A 173 (1998) 259-271.

[11] C. Pham-Huu, N. Keller, G. Ehret, L. J. Charbonniere, R. Ziessel, M. J. Ledoux, J. Mol. Catal. A: Chem. 170 (2001) 155-163.

[12] P. Serp, M. Corrias, P. Kalck, Appl. Catal. A 253 (2003) 337-358. 
[13] F. Simescu-Lazar, V. Meille, F. Bornette, F. Campoli, C. de Bellefon, Catal. Today 249 (2015) 52-58.

[14] A. Solhy, B. F. Machado, J. Beausoleil, Y. Kihn, F.Gonçalves, M. F. R. Pereira, J. J. M. Órfão, J. L. Figueiredo, J. L. Faria, P. Serp, Carbon 46 (2008) 1194-1207.

[15] C. Larabi, W. al Maksoud, K. C. Szeto, O. Boyron, A. Roubaud, P. Castelli, C. C. Santini, J. J. Walter, J. Anal. Appl. Pyrolysis 100 (2013) 81-87.

[16] E. A. Gelder, S. D. Jackson, C. M. Lok, Catal. Lett. 84 (2002) 205-208.

[17] F. Simescu-Lazar, V. Meille, S. Pallier, E. Chaînet, C. de Bellefon, Appl. Catal. A 453 (2013) 28-33.

[18] C. Portet, P. L. Taberna, P. Simon, E. Flahaut, J. Power Sources 139 (2005) 371-378.

[19] K. P. de Jong, J. W. Geus, Catal. Rev. 42 (2000) 481-510.

[20] J.-M. Nhut, L. Pesant, J.-P. Tessonnier, G. Winé, J. Guille, C. PhamHuu, M.-J. Ledoux, Appl. Catal. A 254 (2003) 345-363.

[21] A. Berenguer-Murcia, E. V. Rebrov, M. Cabaj, A. E. H. Wheatley, B. F. G. Johnson, J. Robertson, J. C. Schouten, J. Mater. Sci. 44 (2009) 6563-6570.

[22] L. Truong-Phuoc, T. Truong-Huu, L. Nguyen-Dinh, W. Baaziz, T. Romero, D. Edouard, D. Begin, I. Janowska, C. Pham-Huu, Appl. Catal. A 469 (2014) 81-88.

[23] B. H. Morrow, A. Striolo, J. Phys. Chem. C 111 (2007) 17905-17913.

[24] J. Nakamura, T. Kondo, Top. Catal. 56 (2013) 1560-1568.

[25] J. M. M. Tengco, Y. K. Lugo-José, J. R. Monnier, J. R. Regalbuto, Catal. Today 246 (2015) 9-14. 